\title{
Stres, Motivasi Berprestasi, Bersyukur, dan Perceived Social Support: Analisis Optimisme pada Mahasiswa Penerima Beasiswa Bidikmisi
}

\author{
Sugiarti A Musabiq, Lu'lu Nurrahiimah Assyahidah, Adila Sari, Hervi Utami Kusuma Dewi, \\ Widya Aktivana Erdiaputri \\ musabiqsugiarti2017@gmail.com
}

Fakultas Psikologi, Universitas Indonesia, Depok, Indonesia

\begin{abstract}
This study aimed to investigae the relationship between optimism with stress, gratitude, achievement motivation, and perceived social support on students of Bidikmisi Scholarship, an educational funding for prospective students who could not afford higher education costs yet have excellent academic potential to study at universities on top-tier undergraduate programs for the specified time period. This study used quantitative approach with correlational design. A total of 300 students from four different classes at University of Indonesia participated in this study. Of these, only 253 participant data (70 men and 183 women) could be analyzed. Data were collected by asking participants to complete series of questionnaires consisting of Life Orientation Test-Revised (LOTR) for optimism, Gratitude Questionaire-Six Items (GQ-6) for gratitude, Achievement Motives Scale-Revised (AMS-R) for achievement motivation, Perceived Stress Scale (PSS) for stress, and Social Provisions Scale (SPS) for social support. The results showed a significant relationship between optimism and stress $(r=-0.158 ; p<0.05)$; optimism and achievement motivation $(r=0.15$; $p<0.05)$; optimism and gratitude ( $r=0.267 ; p<0.05)$; and optimism and perceived social support $(r=0.351 ; p<0.05)$. The result reveals that the higher the level of optimism that Bidikmisi Scholarship students have, the higher their gratitude, achievement motivation, and perceived social support become, and the lower the level of their stress will be.
\end{abstract}

Keywords: achievement motivation; gratitude; optimism; perceived social support, stress

Penelitian ini dilakukan untuk menunjukkan hubungan antara optimisme dengan stres, rasa syukur, motivasi berprestasi, dan persepsi dukungan sosial pada mahasiswa penerima Beasiswa Bidikmisi. Penelitian ini merupakan penelitian kuantitatif dengan desain penelitian korelasional. Sebanyak 300 mahasiswa dari empat kelas di Universitas Indonesia berpartisipasi dalam penelitian ini. Dari 300 data, hanya 253 data peserta (70 pria dan 183 wanita) yang bisa diproses. Penelitian dilakukan dengan meminta peserta mengisi kuesioner yang terdiri dari Life Orientation Test-Revised (LOTR) untuk optimisme, Gratitude Questionaire-Six Items (GQ-6) untuk rasa syukur, Achievement Motives Scale-Revised (AMS-R) untuk motivasi berprestasi, Perceived Stress Scale (PSS) untuk stres, dan Social Provisions Scale (SPS) untuk dukungan sosial. Hasil penelitian menunjukkan hubungan yang signifikan antara optimisme dan stres $(\mathrm{r}=-0.158 ; \mathrm{p}<0.05)$; optimisme dan motivasi berprestasi $(\mathrm{r}=0.15 ; \mathrm{p}<0.05)$; optimisme dan rasa syukur $(\mathrm{r}=0.267 ; \mathrm{p}<0.05)$; dan optimisme dan dukungan sosial yang dirasakan $(\mathrm{r}=0.351 ; \mathrm{p}<0.05)$. Hal ini bermakna bahwa semakin tinggi tingkat optimisme mahasiswa, maka semakin tinggi pula rasa syukur, motivasi berprestasi, dan dukungan sosial yang dirasakan, serta semakin rendah tingkat stresnya.

Kata kunci: bersyukur; motivasi berprestasi; optimisme; perceived social support; stres

Received: September 26, 2017 Accepted: April 28, 2018

How to cite: Musabiq, S. A., Assyahidah, L. N., Sari, A., Dewi, H. U. K, \& Erdiaputri, W. A. (2018). Stres, motivasi berprestasi, bersyukur, dan perceived social support: Analisis optimisme pada mahasiswa penerima Beasiswa Bidikmisi. MEDIAPSI, 4(1), 22-35. doi: https://doi.org/10.21776/ub.mps.2018.004.01.3

\section{Pendahuluan}

Pendidikan merupakan hak bagi setiap warga negara Indonesia sebagaimana disebutkan dalam Undang-undang Dasar Negara Republik Indonesia 1945. Di samping itu, pendidikan merupakan hal yang penting 
bagi pertumbuhan ekonomi suatu negara dengan cara meningkatkan kemampuan membaca, keterampilan, dan keahlian tenaga kerja (Blaugh, dalam Ehigiamusoe, 2013). Sayangnya, tidak semua masyarakat Indonesia mampu melanjutkan pendidikan hingga ke jenjang pendidikan tinggi. Berdasarkan angka partisipasi kasar, hanya terdapat $29.4 \%$ pelajar di Indonesia yang melanjutkan pendidikannya hingga ke perguruan tinggi (Direktorat Jenderal Pendidikan Tinggi, 2015). Hal ini terjadi karena tingginya biaya pendidikan yang sulit dijangkau, khususnya bagi masyarakat dengan kondisi ekonomi rendah (Pasaribu, 2014). Padahal bagi masyarakat ekonomi rendah, pendidikan di perguruan tinggi ini sangat dibutuhkan agar mereka dapat lepas dari kemiskinan dan membantu meningkatkan perkembangan ekonomi Indonesia dengan menjadi SDM yang terampil dan berpendidikan. Untuk menanggulangi permasalahan tersebut, pemerintah pun mengeluarkan berbagai bantuan biaya pendidikan untuk melanjutkan pendidikan ke perguruan tinggi, salah satunya dengan mengeluarkan program Beasiswa Bidikmisi pada tahun 2010 .

Beasiswa Bidikmisi merupakan bantuan biaya pendidikan bagi calon mahasiswa yang tidak mampu secara ekonomi dan memiliki potensi akademik yang baik untuk menempuh pendidikan di perguruan tinggi pada program studi unggulan sampai lulus tepat waktu (Direktorat Jenderal Pendidikan Tinggi, 2015). Bantuan biaya yang diberikan berupa bantuan biaya kuliah, uang saku bulanan, hingga pelatihan yang diberikan secara reguler bagi mahasiswa penerima Bidikmisi. Beasiswa Bidikmisi dapat memberikan fasilitas bagi penerimanya agar mereka mampu mencapai cita-citanya dengan menempuh pendidikan di perguruan tinggi. Bantuan tersebut dapat membuat mahasiswa penerima Beasiswa Bidikmisi menjadi lebih yakin bahwa dirinya mampu meraih cita-cita dan tujuan yang diharapkan. Dengan kata lain, mereka menjadi lebih yakin akan datangnya hasil atau hal-hal positif di masa yang akan datang. Keyakinan positif terhadap masa yang akan datang ini disebut dengan optimisme (Scheier \& Carver, 1985).

Optimisme dapat didefinisikan sebagai keyakinan secara umum akan adanya hasil yang baik (Scheier \& Carver, 1985; Scheier, dkk., dalam Scheier \& Carver, 2002). Individu yang optimis memiliki kecenderungan untuk tetap yakin dan selalu berusaha dalam menghadapi segala tantangan dalam hidupnya sesulit dan seberat apapun itu (Scheier \& Carver, 2002). Terkait dengan mahasiswa penerima Beasiswa Bidikmisi, mereka tetap yakin dapat menjalani pendidikan di perguruan tinggi dan dapat meraih cita-citanya meski dihadapkan dengan keadaan ekonomi yang sulit. Hal ini sejalan dengan wawancara yang tim peneliti lakukan terhadap 12 mahasiswa penerima Beasiswa Bidikmisi di Universitas Indonesia (UI) bahwa mereka memiliki keyakinan atas kemampuan mereka dalam berprestasi.

Berdasarkan hasil wawancara juga ditemukan bahwa mahasiswa merasa bersyukur dengan adanya Beasiswa Bidikmisi ini. Ungkapan syukur ini salah satunya terucap dari mahasiswa penerima Bidikmisi, "Saya bersyukur karena Beasiswa Bidikmisi ini dapat membantu saya, harapan saya agar nanti saya bisa cumlaude." Kalimat ini merupakan suatu ungkapan syukur dan keyakinan akan masa depan yang lebih baik dari penerima Bidikmisi. Survei lanjutan tim peneliti menunjukkan bahwa sebagian besar mahasiswa yang menerima Bidikmisi 
mengungkapkan syukur. Ada pula beberapa testimoni dari para penerima Beasiswa Bidikmisi yang mengungkapkan syukurnya melalui website Bidikmisi. Pada website ini tergambar bagaimana mahasiswa-mahasiswa Bidikmisi merasa terbantu dalam bidang finansial, akademis maupun nonakademis selama masa perkuliahan dan selama tinggal jauh dari orangtua. Bersyukur sendiri diartikan sebagai reaksi emosi positif sebagai respon terhadap penerimaan karunia atau keuntungan dari seseorang (Lambert, Graham, \& Fincham, 2009).

Meskipun terdapat banyak keuntungan yang diterima oleh mahasiswa dari beasiswa bidikmisi, masalah individu untuk melanjutkan pendidikan ke jenjang perguruan tinggi tidak serta merta selesai. Terkadang jumlah uang saku yang diberikan tidak sebanding dengan rata-rata pengeluaran mahasiswa penerima Beasiswa Bidikmisi setiap bulan. Oleh sebab itu, mereka harus menyesuaikan jumlah pengeluaran dengan perolehan uang saku dari Beasiswa Bidikmisi seperti dengan cara meminimalkan kebutuhan sehari-hari dan berusaha untuk hidup sederhana. Selain itu, mahasiswa penerima Beasiswa Bidikmisi dihadapkan dengan berbagai tuntutan dan tanggung jawab, baik dari kampus maupun dari pemerintah sebagai pihak yang memberikan beasiswa. Dari pemerintah, mahasiswa Bidikmisi diharuskan untuk menyelesaikan kuliah tepat waktu dengan Indeks Prestasi Kumulatif di atas 3. Selain itu, mahasiswa dituntut untuk aktif berorganisasi. Setiap semester, mereka diwajibkan untuk mengirimkan laporan terkait perkembangan akademik. Selain itu, mahasiswa penerima Beasiswa Bidikmisi juga harus melaporkan kegiatan nonakademis yaitu organisasi yang diikuti, kepanitiaan yang dilakukan, seminar yang diikuti, karya ilmiah yang dibuat, dan prestasi yang diraih (Anonim, 2015). Apabila mahasiswa penerima Beasiswa Bidikmisi tidak memenuhi persyaratan akademis dan nonakademis maka mahasiswa yang bersangkutan akan mendapatkan surat peringatan dan pemberian bantuan beasiswa terancam tidak dilanjutkan.

Berdasarkan penjelasan-penjelasan di atas, dapat diketahui bahwa di tengah keterbatasannya, mahasiswa penerima Beasiswa Bidikmisi dituntut untuk optimal dalam menjalankan tanggung jawabnya, khususnya dalam perkuliahannya. Untuk dapat optimal, mahasiswa diharapkan memiliki motivasi berprestasi yang tinggi (baik secara akademik, maupun nonakademik). Hal ini dilakukan mengingat tuntutan dari pemerintah terhadap penerima Beasiswa Bidikmisi yang cukup tinggi. Motivasi berprestasi sendiri adalah keinginan yang positif untuk menyelesaikan tugas-tugas dalam suasana persaingan untuk memperoleh sukses dengan standar yang tinggi. Menurut Lang dan Fries (2006) dimensi dari motivasi berprestasi terbagi dua yaitu hope of success (harapan untuk sukses) dan fear of failure (ketakutan untuk gagal). Kedua dimensi tersebut dibutuhkan oleh seseorang yang memiliki motivasi berprestasi untuk meraih prestasi. Menurut Lang dan Fries (2006) individu yang memiliki hope of success dapat tampil lebih baik, cenderung lebih bertahan, menikmati pekerjaan yang lebih terkait dengan tugastugas dan prestasi, mengevaluasi diri menjadi lebih positif, menikmati pekerjaan, dan cenderung lebih menyukai tugas realistik dan menantang. Kemudian individu yang memiliki fear of failure lebih khawatir ketika mengerjakan tugas-tugas yang berkaitan dengan prestasi, mengevaluasi diri lebih negatif, dan memiliki kecemasan yang lebih tinggi (Lang \& Fries, 2006). 
Berbagai tuntutan akademis dan nonakademis sebagai mahasiswa penerima Beasiswa Bidikmisi dan ditambah masalah keuangan dapat menjadi sumber stres dan depresi bagi mahasiswa penerima Beasiswa Bidikmisi. Stres merupakan keadaan yang muncul ketika individu merasa bahwa ia tidak dapat secara memadai mengatasi tuntutan yang ditunjukkan pada dirinya atau merasakan adanya ancaman terhadap dirinya (Lazarus, 1966). Lazarus dan Folkman (dalam Smith, Rasmussen, Mills, Wefald, \& Downey, 2012) mengemukakan, bahwa stres mengurangi peforma kerja seseorang. Sementara sebagai mahasiswa penerima Bidikmisi UI, performa yang buruk ketika melakukan kewajiban Bidikmisi-nya dapat berakibat pada pencabutan beasiswa yang diterima serta pemutusan bantuan hidup dan pendidikan mereka. Ancaman akan kemungkinan pencabutan beasiswa ini ikut menjadi tambahan sumber stres mereka.

Terdapat beberapa hal yang dapat mengurangi stres pada mahasiswa penerima Beasiswa Bidikmisi. Berdasarkan hasil wawancara sebelumnya, beberapa partisipan yang mengaku bahwa dukungan yang diperoleh dari lingkungan sekitarnya dapat meringankan beban masalah ataupun stres yang dihadapinya. Dukungan yang didapatkan dari lingkungan sekitar mengacu kepada dukungan sosial atau social support. Social support dapat diartikan sebagai pengalaman ataupun persepsi dari individu bahwa dirinya dicintai dan disayangi, dihargai dan dianggap sebagai bagian dari jaringan sosial yang memiliki kesamaan kebutuhan (Wills, dalam Taylor, dkk, 2004). Akan tetapi tidak semua social support dapat membantu individu dalam mengahadapi masalah ataupun tuntutan yang dihadapinya. Hal tersebut bisa saja terjadi karena dukungan yang didapatkan belum tentu merupakan dukungan yang sebenarnya dibutuhkan oleh individu yang bersangkutan.

Social support terbagi atas dua bentuk, yaitu received support dan juga perceived support (Young, 2006). Received support merupakan pengukuran dari dukungan yang sebenarnya didapatkan dari orang lain, sedangkan perceived support atau perceived social support (PSS) dilihat dengan menanyakan sejauh mana individu meyakini bahwa ia akan dibantu oleh orang-orang yang ada di sekitarnya. Beberapa penelitian sebelumnya membuktikan bahwa sebelum received support diperlukan, perceived support dapat terlebih dahulu membantu individu dalam menghadapi keadaan yang penuh tekanan (stressful life event) menjadi terasa tidak lagi terlalu menekan (less stressful), sehingga hal ini membuat received support menjadi hal yang tidak signifikan dalam situasi tersebut (Srivastava \& Angelo, 2009). Oleh karena itu, PSS menjadi hal yang lebih penting bagi individu dibandingkan dengan received support. Hal ini disebabkan oleh tidak semua dukungan yang diterima individu (received support) dapat membantu individu tersebut dalam menghadapi berbagai masalah yang dihadapinya. Dalam konteks mahasiswa penerima Beasiswa Bidikmisi di UI, dukungan yang didapatkan dari orangorang yang berada di lingkungan sekitarnya ataupun dukungan yang diperoleh dari pemerintah berupa Beasiswa Bidikmisi, belum tentu dapat membantu mereka dalam menghadapi berbagai tuntutan dan masalah yang dihadapinya. Persepsi akan ketersediaan dukungan bisa jadi lebih berperan bagi mahasiswa penerima Beasiswa Bidikmisi di UI dalam menghadapi berbagai tuntutan dan masalahnya tersebut. Ketika individu dapat mengatasi masalah yang dihadapinya, hal ini akan diikuti dengan munculnya keyakinan 
akan datangnya hasil positif di masa yang akan datang.

Munculnya optimisme pada mahasiswa penerima Beasiswa Bidikmisi akan masa depan yang lebih baik, lalu timbulnya rasa bersyukur atas karunia yang telah diberikan, serta dengan optimisme tersebut diharapkan mampu memicu individu memiliki motivasi berprestasi yang tinggi, membuat peneliti menduga adanya keterkaitan antara variabelvariabel ini, yaitu antara optimisme dengan rasa bersyukur serta dengan motivasi berprestasi. Selain itu, peneliti juga menduga adanya keterkaitan antara optimisme dan stres serta perceived social support. Adanya stres yang dihadapi serta adanya persepsi dukungan sosial yang akan diterima juga dapat memengaruhi tingkat optimisme individu, begitu pula sebaliknya. Dengan kata lain, peneliti menduga adanya keterkaitan antara variabel optimisme dengan rasa bersyukur, motivasi berprestasi, stres, dan perceived sosial support.

Dugaan ini sejalan dengan beberapa penelitian sebelumnya. Pada penelitian yang dilakukan oleh McCullough, Emmons, dan Tsang (2002) ditemukan bahwa orang yang bersyukur memiliki tingkat emosi positif, kepuasan hidup, vitalitas, dan optimisme yang lebih tinggi. Penelitian tersebut menunjukkan bahwa terdapat hubungan antara optimisme dan bersyukur. Dengan bersyukur, mahasiswa dapat lebih menghargai keberuntungan yang didapatkan. Keberuntungan tersebut membawa mahasiswa penerimanya menjadi lebih optimis terhadap apa yang ada di depan matanya. Pada hubungannya dengan motivasi berprestasi, optimisme mampu meningkatkan prestasi akademis (Tripathi \& Chaturvedi, 2014). Hasil penelitian tersebut sejalan dengan hasil penemuan lain bahwa optimisme berhubungan signifikan dengan prestasi (Yates, 2000). Selain optimisme, motivasi berprestasi ternyata juga berhubungan dengan prestasi. Hasil penelitian Awan, Noureen, dan Naz (2011) menunjukkan prestasi seseorang berhubungan signifikan dengan motivasi berprestasi. Goleman (dalam Singh \& Jha, 2013) menyebutkan untuk performa akademis yang bagus dibutuhkan optimisme dan motivasi berprestasi.

Dalam kaitannya dengan stres, penelitian sebelumnya menemukan bahwa stres dan depresi berhubungan dengan optimisme. Orang yang optimis lebih dapat menghadapi situasi yang sulit dibandingkan orang yang pesimis dan mengalami stres yang lebih sedikit (Jones, dkk, dalam McBride, 2012). Selain menurunkan risiko stres, optimisme juga dapat meningkatkan kemampuan coping individu yang mengalami situasi sulit (Tripathi \& Chaturvedi, 2014). Kemudian, optimisme juga memiliki korelasi dengan depresi. Hasil penelitian menunjukkan bahwa orang yang optimis dilaporkan memiliki level depresi yang rendah dibandingkan dengan orang pesimis (Shower \& Ruben, dalam Maatta, Nurmi, \& Stattin, 2007). Terhadap perceived social support, ditemukan hubungan antara optimisme dan perceived social support pada dewasa akhir (Ferguson \& Goodwin, 2010; Park \& Folkman, dalam Brisette, Scheier, \& Carver, 2002).

Pentingnya optimisme dimiliki oleh mahasiswa penerima Beasiswa Bidikmisi, serta pentingnya mereka memiliki motivasi berprestasi yang cukup tinggi, memiliki tingkat stres yang rendah, memiliki persepsi terhadap dukungan sosial yang tinggi, serta rasa bersyukur yang tinggi dalam menjalani kehidupan perkuliahan dengan segala target yang ditetapkan dan dengan segala tantangan 
serta keterbatasan yang ada, membuat peneliti tertarik untuk melakukan penelitian ini. Terlebih lagi, belum adanya penelitian yang mengaitkan antar variabel ini dalam konteks Indonesia, khususnya dengan partisipan seperti pada penelitian ini. Penelitian ini dilakukan pada mahasiswa penerima Beasiswa Bidikmisi di Universitas Indonesia. Universitas Indonesia dipilih karena letak geografis Universitas Indonesia yang berada di kota besar dan membutuhkan biaya hidup tinggi dengan persaingan akademik yang ketat sehingga memungkinkan mahasiswa penerima Beasiswa Bidikmisi ini untuk pesimis, memiliki tingkat stres yang tinggi, motivasi berprestasinya menurun, membutuhkan dukungan sosial yang tinggi, dan cenderung tidak bersyukur. Adapun pertanyaan penelitian yang ingin dijawab yaitu apakah terdapat hubungan yang signifikan antara optimisme dan bersyukur, motivasi berprestasi, stres, dan perceived social support?

\section{Metode}

\section{Desain dan partisipan penelitian}

Penelitian ini merupakan penelitian kuantitatif dan korelasional. Karakteristik partisipan dalam penelitian ini yaitu mahasiswa penerima Beasiswa Bidikmisi di UI angkatan kuliah tahun pertama hingga keempat yang masih aktif sebagai mahasiswa dan masih menerima Beasiswa Bidikmisi. Pengambilan sampel (sampling) dalam penelitian ini menggunakan teknik convenience sampling atau accidental sampling. Selain itu, peneliti juga menggunakan teknik snowball yaitu proses pemilihan sampel berdasarkan koneksi atau jaringan (Kumar, 2005). Pada penelitian ini, peneliti menargetkan untuk mendapatkan 300 sampel. Akan tetapi, peneliti hanya mendapatkan 261 sampel.

\section{Instrumen penelitian}

\section{Optimisme}

Pengukuran optimisme menggunakan Life Orientation Test-Revised (LOT-R) dari Scheier, Carver, dan Bridges (1994) yang telah diadaptasi ke dalam Bahasa Indonesia. Alat ukur optimisme ini terdiri dari sepuluh butir yang mengukur optimisme dan pesimisme seseorang. Butir alat ukur yang digunakan setelah diuji coba yaitu sebanyak enam butir. Pada penelitian ini, partisipan dapat memilih satu jawaban dari enam pilihan jawaban pada masing-masing butir yang dimaknai sebagai berikut: "1" (Sangat Tidak Setuju), "2" (Tidak Setuju), “3” (Agak Tidak Setuju), "4” (Agak Setuju), "5" (Setuju), dan "6" (Sangat Setuju).

\section{Bersyukur (gratitude)}

Pengukuran variabel bersyukur menggunakan alat ukur Gratitude Questionaire-Six Items (GQ-6) dari McCullough, Emmons, dan Tsang (2002). Butir-butir dalam GQ-6 memiliki empat faset yang mengukur disposisi bersyukur, yaitu gratitude intensity, gratitude frequency, dan gratitude span. Koefisien reliabilitas pada GQ6 yaitu sebesar 0,82. Menurut Kaplan dan Saccuzo (2005) reliabilitas yang berada pada rentang 0,7 hingga 0,8 dinilai cukup baik. Pada tiap butir, partisipan diminta memilih satu dari tujuh jawaban yang disediakan yaitu "1" (Sangat Tidak Sesuai), "2" (Tidak Sesuai), “3” (Agak Tidak Sesuai), "4" (Netral), "5” (Agak Sesuai, “6” (Sesuai), dan “7” (Sangat Sesuai).

\section{Motivasi berprestasi}

Alat ukur yang digunakan untuk mengukur motivasi berprestasi pada penelitian ini adalah alat ukur Achievement Motives Scale-Revised (AMS-R) oleh Lang dan Fries (2006). Alat ukur ini terdiri dari 10 butir yang disusun berdasarkan revisi dari Achievement 
Motives Scale (AMS) oleh Gjesme dan Nygard (dalam Lang \& Fries, 2006) yang terdiri dari 30 butir. Alat ukur ini kemudian diadaptasi ke Bahasa Indonesia. Alat ukur ini memiliki dua dimensi yaitu hope of success (HS) dan fear of failure (FF).

Stres

Pengukuran stres menggunakan Perceived Stress Scale (PSS) yang dikembangkan oleh Cohen (1988) dan diadptasi ke dalam Bahasa Indonesia. Alat ukur ini berjumlah 10 butir dengan 5 respon dalam skala Likert, yaitu "Tidak Pernah", "Hampir Tidak Pernah", "Kadang-kadang", "Cukup Sering”, dan "Sangat Sering".

\section{Perceived social support}

Pengukuran perceived social support menggunakan Social Provisions Scale (SPS) (Cutrona \& Russell, 1987) yang telah diadaptasi ke dalam bahasa Indonesia dan diuji kembali validitas dan reliabilitasnya. Alat ukur ini terdiri dari enam aspek dengan jumlah butir sebanyak empat butir di setiap aspek. Aspek yang terdapat dalam alat ukur ini yaitu guidance, reliable alliance, reassurance of worth, attachment, social integration, dan opportunity of nurturance.

\section{Teknik analisis data}

Data yang telah terkumpul kemudian diolah secara kuantitatif menggunakan Program Statistical Package for Social Science (SPSS) dengan teknik statistik deskriptif dan korelasi Pearson untuk melihat signifikansi hubungan linear antara variabel.

\section{Hasil}

Sebanyak 300 mahasiswa berpartisipasi dalam penelitian ini. Dari 300 data tersebut, sebanyak 253 data yang dapat dilanjutkan untuk dianalisis. Tabel 1 menunjukkan bahwa sebanyak 70 partisipan adalah laki-laki dan 183 partisipan adalah perempuan. Hal ini menunjukkan bahwa sebagian besar partisipan adalah perempuan. Berdasarkan angkatan, jumlah partisipan terbanyak berada pada angkatan pertama, yaitu sebanyak 118 orang (46.6\%). Partisipan yang berasal dari angkatan lainnya yaitu 46 orang (18.1\%) angkatan kedua, 42 orang (16.6\%) angkatan ketiga, serta 47 orang $(18.57 \%)$ angkatan keempat.

Tabel 1

Data Demografi Partisipan

\begin{tabular}{lcc}
\hline & Frekuensi & Persentase \\
\hline Jenis Kelamin & 70 & $27.67 \%$ \\
Laki-laki & 183 & $72 . .33 \%$ \\
Perempuan & & \\
\hline Angkatan & 118 & $46.6 \%$ \\
Pertama & 46 & $18.1 \%$ \\
Kedua & 42 & $16.6 \%$ \\
Ketiga & 47 & $18.57 \%$ \\
Keempat & penelitian & sebagaimana
\end{tabular}

ditunjukkan pada Tabel 2 menunjukkan bahwa terdapat hubungan yang signifikan antara optimisme dan stres $(\mathrm{r}=-0.158 ; \mathrm{p}<0.05)$; optimisme dan motivasi berprestasi $(\mathrm{r}=0.15$; $\mathrm{p}<0.05$ ); optimisme dan bersyukur ( $\mathrm{r}=0.267$; $\mathrm{p}<0.05)$; serta optimisme dan perceived social support $(\mathrm{r}=0.351 ; \mathrm{p}<0.05)$.

Tabel 2

Hasil Korelasi Keseluruhan

\begin{tabular}{lcc}
\hline & \multicolumn{2}{c}{ Optimisme } \\
\cline { 2 - 3 } & $\mathbf{r}$ & Sig $(\boldsymbol{p})$ \\
\hline Stres & -0.158 & $0.01^{*}$ \\
Motivasi Berprestasi & 0.15 & $0.018^{*}$ \\
Bersyukur & 0.267 & $0.000^{*}$ \\
Perceived Social Support & 0.351 & $0.000^{*}$ \\
\hline
\end{tabular}

*sig pada LoS 0.05

Tabel 3

Hasil Korelasi Per Dimensi 


\begin{tabular}{lcc}
\hline & \multicolumn{2}{c}{ Optimisme } \\
\cline { 2 - 3 } & $\mathbf{r}$ & $\operatorname{sig}(\boldsymbol{p})$ \\
\hline Perceived Social Support & & \\
$\quad$ Guidance & 0.265 & $0.000^{*}$ \\
$\quad$ Reassurance of Worth & 0.177 & $0.005^{*}$ \\
Social Integration & 0.268 & $0.000^{*}$ \\
Attachment & 0.281 & $0.000^{*}$ \\
$\quad$ Opportunity of Nurturance & 0.290 & $0.000^{*}$ \\
$\quad$ Reliable Alliance & 0.291 & $0.000^{*}$ \\
\hline Motivasi Berprestasi & & \\
$\quad$ Hope of Success & 0.216 & $0.001^{*}$ \\
$\quad$ Fear of Failure & 0.025 & 0.701 \\
\hline
\end{tabular}

*sig pada LoS 0.05

Pada hubungan antara optimisme dan aspek perceived social support, terdapat hubungan yang signifikan antara optimisme dengan aspek guidance $(\mathrm{r}=0.265 ; \mathrm{p}<0.05)$, reassurance of worth $(\mathrm{r}=0.177 ; \mathrm{p}<0.05)$, social integration $(\mathrm{r}=0.268 ; \mathrm{p}<0.05)$, attachment $(\mathrm{r}=0.281 ; \mathrm{p}<0.05)$, opportunity of nurturance $(\mathrm{r}=0.290 ; \mathrm{p}<0.05)$, serta relliable alliance $(\mathrm{r}=0.291 ; \mathrm{p}<0.05)$. Untuk hubungan antara optimisme dan dimensi motivasi berprestasi, terdapat hubungan antara optimisme dan motivasi berprestasi dimensi hope of success $(\mathrm{r}=0.216 ; \quad \mathrm{p}<0.05) \quad$ serta tidak terdapat hubungan antara optimisme dan motivasi berprestasi pada dimensi fear of failure $(\mathrm{r}=0.025 ; \mathrm{p}>0.05)$.

\section{Diskusi}

Tujuan utama dari penelitian ini adalah untuk mengetahui hubungan antara optimisme dengan bersyukur, motivasi berprestasi, stres, dan perceived social support. Hasil penelitian mengindikasikan bahwa terdapat hubungan yang signifikan dan positif antara optimisme dengan bersyukur, motivasi berprestasi, dan perceived social support. Hal ini berarti bahwa semakin tinggi tingkat optimisme mahasiswa penerima Beasiswa Bidikmisi, maka semakin tinggi pula tingkat bersyukur, motivasi berprestasi, dan perceived social support, begitu pula sebaliknya. Semakin rendah tingkat optimisme individu, maka semakin rendah pula tingkat bersyukur, motivasi berprestasi, dan perceived social support. Hasil penelitian ini juga mengindikasikan bahwa terdapat hubungan yang signifikan negatif antara optimisme dan stres. Hal ini berarti bahwa semakin tinggi tingkat optimisme mahasiwa penerima beasiswa bidikmisi, maka semakin rendah pula tingkat stresnya, begitu pula sebaliknya. Semakin rendah tingkat optimisme, maka semakin tinggi pula tingkat stresnya.

Adanya korelasi yang positif dan signifikan antara optimisme dan bersyukur sesuai dengan penelitian yang dilakukan sebelumnya oleh McCullough, Emmons, dan Tsang (2002) bahwa kedua variabel memiliki korelasi positif yakni tingkat optimisme berbanding lurus dengan bersyukur. Adanya korelasi tersebut juga mengindikasikan karakteristik partisipan mahasiswa Bidikmisi memiliki andil untuk menghubungkan optimisme dan bersyukur di mana pada penelitian sebelumnya belum ditemukan pada karakteristik populasi ini. Alat ukur yang digunakan dalam penelitian ini berbeda dengan penelitian sebelumnya. Penelitian ini menggunakan alat ukur LOT-R untuk mengukur optimisme, sedangkan pada penelitian sebelumnya menggunakan LOT. Penggunaan alat ukur LOT-R dapat menyempurnakan alat ukur LOT sebagai pendahulunya.

Adanya korelasi yang signifikan dan negatif antara optimisme dan stres sesuai dengan penelitian yang dilakukan oleh Chang (2002) pada dua kelompok dewasa muda dan dewasa tua. Pada kedua kelompok tersebut 
ditemukan hasil korelasi yang signifikan antara optimisme-pesimisme dan stres. Pandangan hidup yang optimistis diasosiasikan dengan dengan stres yang lebih rendah, kualitas hidup yang lebih baik, kesehatan yang lebih baik, dan reaktivitas tekanan darah lebih rendah dibandingkan dengan individu yang memiliki pandangan hidup lebih pesimistis (Raja, Rowe, Kimble, \& Zerwic, dalam Boro \& Dhanalakshimi, 2014).

Adanya hasil penelitian yang signifikan antara optimisme dan motivasi berprestasi sejalan dengan penelitian dari Asawa, dkk, (2011) bahwa terdapat hubungan antara optimisme dan motivasi berprestasi. Berdasarkan hasil korelasi antara optimisme dan dimensi-dimensi motivasi berprestasi, dapat disimpulkan bahwa terdapat hubungan yang signifikan dan positif antara optimisme dan motivasi berprestasi dimensi hope of success pada mahasiswa penerima Beasiswa Bidikmisi di Universitas Indonesia. Hasil ini menunjukkan bahwa semakin tinggi tingkat optimisme individu, maka motivasi berprestasi pada dimensi hope of success juga tinggi. Menurut Belanger, Lafreniere, Vallerand, dan Kruglanski (2013) hope of success adalah percaya pada kesuksesan. Ketika memiliki hope of success, individu merasa selalu ingin mengerjakan tugas dengan baik (Pang, Villacorta, Chin, \& Morrison, dalam Belanger, dkk, 2013).

Berdasarkan hasil temuan penelitian ini pula, terdapat hubungan motivasi berprestasi dan hope of success, sehingga mahasiswa Bidikmisi UI yang optimis juga memiliki harapan yang tinggi untuk sukses. Kemudian tidak terdapat hubungan yang signifikan antara optimisme dan motivasi berprestasi pada dimensi fear of failure pada mahasiswa penerima Beasiswa Bidikmisi di Universitas
Indonesia. Fear of failure muncul ketika ada kemungkinan akan gagal saat mengerjakan tugas (Elliot \& Church, 1997). Fear of failure diasosiasikan dengan pesimis, menarik diri dan prokrastinasi (Elliot \& Church, dalam Belanger, dkk, 2013). Pada penelitian ini tidak ditunjukkan hasil bahwa mahasiswa penerima Beasiswa Bidikmisi yang optimis juga akan menghindari kegagalan. Mahasiswa penerima Beasiswa Bidikmisi dapat menganggap kegagalan bukan hal yang memalukan seperti yang dikemukakan oleh Elliot (dalam Belanger, dkk, 2013) namun sebagai batu loncatan untuk meraih kesuksesan. Dari kegagalan, seseorang dapat belajar dari kesalahan sebelumnya untuk menjadi lebih baik di masa mendatang. Menurut Lange dan Crusius (2015) fear of failure mengarahkan untuk menghindari kegagalan dengan cara tidak melakukannya. Hal ini menunjukkan bahwa mahasiswa penerima Bidikmisi di UI tidak menghindari kegagalan untuk mencapai kesuksesan. Mereka tetap optimis dapat melakukan dan yakin berhasil walaupun tingkat keberhasilannya rendah. Penemuan ini dapat dikaitkan dengan keterbatasan keuangan dan tuntutan yang banyak pada mahasiswa penerima Bidikmisi. Di tengah kekurangan uang dan banyaknya tuntutan, mahasiswa penerima Bidikmisi harus tetap optimis agar tidak menimbulkan stres dan depresi.

Adanya hasil yang signifikan dan positif antara optimisme dan perceived social support sejalan dengan penelitian yang dilakukan oleh Park dan Folkman (dalam Brisette, Scheier \& Carver, 2002), yang menyatakan bahwa tingkat optimisme yang tinggi berhubungan dengan tingkat PSS yang tinggi. Dalam sumber yang sama juga disebutkan bahwa seorang yang optimis memiliki kecenderungan untuk memiliki tingkat social support yang lebih tinggi. Hubungan antara optimisme dan 
PSS ini menurut Brisette, Scheier dan Carver (2002) mungkin saja terjadi karena optimisme yang tinggi dapat menjadi salah satu faktor berkembangnya lingkungan sosial yang luas dan penuh dukungan (suportif). Apabila individu memiliki keyakinan bahwa hasil yang baik akan datang, maka keyakinan tersebut dapat membuatnya memiliki persepsi yang lebih positif terhadap lingkungan serta interaksi sosialnya. Hal ini mungkin saja terjadi karena ia merasa bahwa lingkungan sosial atau interaksi sosialnya dapat membantunya dalam menghadapi kesulitan yang ia hadapi tersebut. Begitu pula sebaliknya, apabila individu tidak memiliki keyakinan bahwa hasil baik yang ia harapkan akan datang, maka mungkin saja hal tersebut dapat membuatnya memiliki persepsi bahwa ia tidak mendapatkan dukungan dari lingkungan dan interaksi sosialnya. Optimisme juga dapat membantu individu dalam menjalani hubungan sosial dan interpersonal dengan orang lain serta dapat menurunkan kemungkinan munculnya interaksi sosial dan interpersonal yang negatif (Srivastava \& Angelo, 2009).

Pada perceived social support, aspek yang memiliki nilai korelasi paling tinggi adalah reliable alliance. Hasil tersebut menunjukkan bahwa aspek reliable alliance merupakan aspek yang paling berhubungan dengan optimisme pada mahasiswa penerima Beasiswa Bidikmisi. Aspek reliable alliance merupakan suatu keyakinan bahwa ada orang lain yang dapat diandalkan untuk memberikan bantuan yang nyata dan terlihat (tangible) dan biasanya reliable alliance diperoleh dari anggota keluarga (Weiss, dalam Cutrona \& Russell, 1987). Korelasi tersebut mungkin ditemui pada mahasiswa penerima Beasiswa Bidikmisi di UI karena karakteristik umum dari populasi. Maksud dari karakteristik umum di sini adalah mereka merupakan mahasiswa, di mana sebagian besar mahasiswa masih bergantung kepada keluarga, khususnya orang tua. Dukungan dalam bentuk tangible dari keluarga masih merupakan suatu hal yang penting bagi mereka. Selain dari keluarga, menurut Russell, dkk (dalam Cutrona \& Russell, 1987), teman juga menjadi salah satu sumber diperolehnya aspek reliable alliance. Terkait dengan temuan pada penelitian ini, reliable alliance menjadi aspek yang memiliki hubungan paling besar dengan optimisme diantara aspek-aspek PSS lainnya dikarenakan adanya bantuan nyata (tangible) yang diberikan oleh teman partisipan seperti misalnya bantuan dalam menyelesaikan tugas, belajar bersama, dan lain sebagainya. Bantuanbantuan seperti itu biasa didapatkan oleh mahasiswa dari teman-temannya ketika dibutuhkan, sehingga pada akhirnya hal tersebut akan memunculkan keyakinan bahwa individu tersebut akan mendapatkan bantuan nyata dari teman. Keyakinan inilah yang berhubungan dengan optimisme.

Adanya hasil penelitian ini menjadi hasil penting bagi penelitian optimisme, khususnya pada mahasiswa penerima beasiswa dengan ekonomi rendah namun berprestasi yang dalam konteks ini yaitu mahasiswa penerima Beasiswa Bidikmisi. Adanya hubungan yang signifikan antara optimisme dengan seluruh variabel utama dalam penelitian ini menunjukkan bahwa seluruh variabel tersebut dapat digunakan untuk meningkatkan optimisme, begitu pula sebaliknya. Khusus untuk variabel stres, peningkatan optimisme digunakan untuk menurunkan tingkat stres pada mahasiswa. Hasil penelitian ini dapat memberikan pengetahuan mengenai apa saja yang dapat dilakukan dan siapa saja yang dapat terlibat dalam meningkatkan optimisme pada mahasiswa penerima Beasiswa Bidikmisi. 
Misalnya, untuk meningkatkan optimisme, mahasiswa membutuhkan dukungan sosial dari teman sehingga penting bagi mahasiswa untuk menjalin hubungan yang baik dengan teman. Hal lainnya yaitu apabila mahasiswa ingin meningkatkan optimisme dari dirinya sendiri, maka hal yang dapat dilakukan adalah memperbanyak rasa syukur atas karunia yang telah diberikan kepadanya selama ini.

Meskipun telah ditemukan hubungan yang signifikan antar variabel, penelitian ini belum menjelaskan variabel mana yang berperan besar terhadap optimisme serta bagaimana interaksi antar variabel tersebut. Oleh sebab itu, pada penelitian selanjutnya sebaiknya dilakukan penelitian untuk memperbaiki hal tersebut. Selain itu, jika telah ditemukan interaksi antara variabel penelitian selanjutnya dapat dilakukan untuk membuat model intervensi yang efektif bagi peningkatan optimisme mahasiswa penerima Beasiswa Bidikmisi.

\section{Daftar Pustaka}

Anonim. (2015). Pedoman Penyelenggaraan Bantuan Biaya Pendidikan Bidikmisi Tahun 2015. Jakarta: Direktorat Jenderal Pembelajaran dan Kemahasiswaan Kementrian Riset Teknologi dan Pendidikan Tinggi. Diambil dari www.bidikmisi.ui.ac.id.

Asawa, K., Chaturvedi, P., Tak, M., Nagarajappa, R., Bhat, N., Bapat, S., Gupta, V., \& Jalihal, S. (2011). Association between educational achievements, career aspiration, achievement motives and oral hygiene behavior among dental student of Udaipur India. Ethiopian Journal Health Science, 24(4), 291-298. doi: https://doi.org/10.4314/ejhs.v24i4.3

Awan, R., Noureen, G., \& Naz, A. (2011). A study of relationship between achievement motivation, self concept and achievement in English and mathematics at secondary level. International Education Studies, 4(3), 72-79. doi: https://doi.org/10.5539/ies.v4n3p72

Belanger, J. J., Lafreniere, M. K., Vallerand, R. J., \& Kruglanski, A. W. (2013). Driven by fear: The effect of success and failure information on passionate individual performance. Journal of Personality and Social Psychology, 104(1), 180-195. doi: https://doi.org/10.1037/a0029585

Boro, J., \& Dhanalakshmi, D. (2014). Life stress, optimism, and life satisfaction among school students. Indian Journal of Positive Psychology, 5(1), 41-45. Diambil dari https://www.questia.com/library/journal /1P3-3466313971/life-stress-optimismand-life-satisfaction-among

Brisette, I., Scheier, M. F., \& Carver, C. S. (2002). The role of optimism in social network development, coping, and psychological adjustment during a life transition. Journal of Personality and Social Psychology, 82(1), 102-111. doi: https://doi.org/10.1037/0022$\underline{3514.82 .1 .102}$

Chang, E. C. (2002). Optimism-pessimism and stress appraisal: Testing a cognitive interactive model of psychological adjustment in adults. Cognitive Therapy and Research, 26(5), 675-690. doi: https://doi.org/10.1023/A:10203134278 $\underline{84}$ 
Cohen, S. (1988). Perceived stress in a probability sample of the United States. Dalam S. Spacapan \& S. Oskamp (Eds.), Claremont Symposium on Applied Social Psychology: The Social Psychology of Health (hal. 31-67). Thousand Oaks, CA, US: Sage Publications, Inc.

Cutrona, C. E., \& Russell, D. W. (1987). The provisions of social relationships and adaptation to stress. Dalam W. H. Jones \& D. Perlman (Eds.), Advances in Personal Relationships Volume 1 (hal. 37-67). Greenwich, CT: JAI Press, Inc.

Direktorat Jenderal Pendidikan Tinggi. (2015). Portal Informasi dan Pendaftaran Bidikmisi. Jakarta: Kementerian Riset, Teknologi, dan Pendidikan Tinggi.

Ehigiamusoe, U. K. (2013). Education, economic growth \& poverty rate in nigeria: Any nexus? Journal of Social and Development Sciences, 4(12), 544553. Diambil dari https://ifrnd.org/journal/index.php/jsds/ article/view/797/797

Elliot, A. J., \& Church, M. A. (1997). A hierarchical model of approach and avoidance achievement motivation. Journal of Personality and Social Psychology, 72(1), 218-232. doi: https://doi.org/10.1037/0022$\underline{3514.72 .1 .218}$

Ferguson, S. J., \& Goodwin, A. D. (2010). Optimism and well-Being in older adults: The mediating role of social support and perceived control. The International Journal of Aging and Human Development, 71(1), 43-68. doi: https://doi.org/10.2190/AG.71.1.c

Kaplan, R. M., \& Saccuzzo, D. P. (2005). Psychological Testing Principles,
Application and Issue (6th Edition). Belmont, CA: Wadsworth.

Kumar, R. (2005). Research Methodology. London: SAGE Publications.

Lang, J. W. B., \& Fries, S. (2006). A revised 10-item version of the Achievement Motives Scale. European Journal of Psychological Assessment, 22, 216-224. doi: $\quad$ https://doi.org/10.1027/1015$\underline{5759.22 .3 .216}$

Lambert, N. M., Graham, S. M., \& Fincham, F. D. (2009). A protptype analysis of gratitude: Varieties of gratitude experiences. Society for Personality and Social Psychology, 35(9), 1193-1207. doi:

https://doi.org/10.1177/0146167209338 $\underline{071}$

Lange, J., \& Crusius, J. (2015). Dispositional envy revisited: Unreveling the motivational dynamics of benign and malicious envy. Personality and Social Psychology Bulletin, 41(2), 284-294. doi:

https://doi.org/10.1177/0146167214564 $\underline{959}$

Lazarus, R. S. (1966). Psychological Stress and the Coping Process. New York: McGraw-Hill.

McBride, M. L. (2012). Examining hope, selfefficacy, and optimism as a motivational cognitive set predicting academic achievement and general weel-being in diverse educational setting (Disertasi Doktoral). Alabama: University of Alabama.

McCullough, M. E., Emmons, R. A., \& Tsang, J. A. (2002). The grateful disposition: A conceptual and empirical topography. 
Journal of Personality and Social Psychology, 82(1), 112-127. doi: https://doi.org/10.1037/00223514.82.1.112

Maatta, S., Nurmi, J., \& Stattin, H. (2007). Achievement orientations, school adjustment, and well-being: A longitudinal study. Journal of Research on Adolescence, 17(4), 789-812. doi: https://doi.org/10.1111/j.15327795.2007.00547.x

Pasaribu, S. (2014). Pengaruh Kondisi Ekonomi Orangtua dan Pendidikan Orangtua terhadap Motivasi Melanjutkan Pendidikan ke Perguruan Tinggi pada Siswa Kelas XI SMA Negeri 1 Garoga Tahun Ajaran 2013/2014 (Skripsi). Medan: Universitas Negeri Medan.

Scheier, M., Carver, C. S., \& Bridges, M. W. (1994). Distinguishing optimism from neuroticism (and trait anxiety, self mastery, dan self-esteem): A reevaluation of the Life Orientation Test. Journal of Personality and Social Psychology, 67(6), 1063-1078. doi: https://doi.org/10.1037/00223514.67.6.1063

Scheier, M., \& Carver, C. S. (1985). Optimism, coping and health: Assessment and implications of generalized outcomes expectancies. Health Psychology, 4(3), 219-247. doi: https://doi.org/10.1037/0278-

$\underline{6133.4 .3 .219}$

Scheier, M. F., \& Carver, C. S. (2002). Optimism. Dalam C. R. Snyder \& S. J. Lopez (Eds.), Handbook of Positive Psychology (hal. 231-255). New York: Oxford University Press.
Singh, I., \& Jha, A. (2013). Anxiety, optimism, and academic achievement among students of private medical and engineering colleges: A comparative study. Journal of Educational and Developmental Psychology, 3(1), 222233.

doi:

https://doi.org/10.5539/jedp.v3n1p222

Smith, M. R., Rasmussen, J. L., Mills, M. J., Wefald, A. J., \& Downey, R. G. (2012). Stress and performance: Do service orientation and emotional energy moderate the relationship? Journal of Occupational Health Psychology, 17(1), 116-128. doi: https://doi.org/10.1037/a0026064

Srivastava, S., \& Angelo, K. M. (2009). Optimism, effects on relationships. Dalam H. T. Reis dan S. Sprecher (Eds.), Encyclopedia of Human Relationships (hal. 1182-1184). Thousand Oaks, CA: SAGE Publications, Inc. doi: https://doi.org/10.4135/9781412958479. n383

Taylor, S. E., Sherman, D. K., Kim, H. S., Jarcho, J., Takagi, K., \& Dunagan, M. S. (2004). Culture and social support: Who seeks it and why? Journal of Personality and Social Psychology, 87(3), 354-362. doi: $\quad$ http://dx.doi.org/10.1037/00223514.87.3.354

Tripathi, A., \& Chaturvedi, K. R. (2014). Optimism: A factor intrinsic motivation and achievement. African International Journal of Research in Management, 2(4), 1-8. Diambil dari http://www.ifsmrc.org/sites/default/files /journals/pdf/2AIJRM\%2002V2N4JD1. pdf

Yates, S. M. (2000, December). Student 


\section{MUSABIQ DKK.}

optimism and pessimism during the transition to co-education. Paper presented at the Australian Association for Research in Education Conference, Sydney, Australia.

Young, K. W. (2006). Social support and life satisfaction. International Journal of Psychosocial Rehabilitation, 10(2), 155-

164. Diambil dari http://www.psychosocial.com/IJPR_10/ Social_Support_and_QOL7_Young.htm $\underline{1}$ 